\title{
Erratum: TRF1 is a stem cell marker and is essential for the generation of induced pluripotent stem cells
}

Ralph P. Schneider, lanire Garrobo, Miguel Foronda, Jose A. Palacios, Rosa M. Marión, Ignacio Flores, Sagrario Ortega \& Maria A. Blasco

Nature Communications 4:1946 doi: 10.1038/ncomms2946 (2013); Published 5 Jun 2013; Updated 6 Sep 2013

The affiliation details for Ignacio Flores are incorrect in this Article and represent the author's present address instead of the address at which the work was carried out. The correct affiliation details for this author are given below:

Telomeres and Telomerase Group, Molecular Oncology Program, Spanish National Cancer Research Centre (CNIO), Melchor Fernández Almagro 3, Madrid E-28029, Spain. Present address: Regeneration and Aging group, Cardiovascular Development and Repair Program, Spanish National Center for Cardiovascular Research (CNIC), Melchor Fernández Almagro 3, Madrid E-29029, Spain. 